\title{
Validation of assays for inflammatory mediators in exhaled breath condensate
}

\author{
D.L. Bayley*, H. Abusriwil*, A. Ahmad* and R.A. Stockley ${ }^{\#}$
}

\begin{abstract}
The use of exhaled breath condensate (EBC) as a tool for noninvasive assessment of lung inflammation is becoming commonplace. Many authors use commercial ELISA kits to measure inflammatory mediators within EBC. However, the very low concentrations of mediators within EBC are often below the commercially validated concentration range of the relevant ELISA and crucially below the linear part of the sigmoid standard curve. The present study seeks to validate a series of assays for use in EBC and to compare the results in EBC with those from matched sol phase sputum samples.

The following mediators were measured by ELISA: leukotriene (LT)B $B_{4}$, interleukin (IL)-8, secretory leukoprotease inhibitor and $\alpha_{1}$-antitrypsin (AAT). Myeloperoxidase was measured by chromogenic substrate assay.

Mediator concentrations reached the lower limit of quantification in only one assay (AAT) in $19.6 \%$ of subjects, while mediator concentrations reached the lower limit of detection in three assays (LTB 4 , IL-8 and AAT in $31,6.5$ and $61 \%$ of subjects, respectively). No significant correlations were present between any mediators in EBC and sol phase sputum.

The results of the present study indicate that care must be exercised when interpreting mediator measurements in exhaled breath condensate and that assays must be validated at concentrations relevant to those found within the biological fluid.
\end{abstract}

KEYWORDS: $\boldsymbol{\alpha}_{1}$-Antitrypsin, exhaled breath condensate, interleukin-8, leukotriene $B_{4}$, myeloperoxidase, secretory leukoprotease inhibitor

R ecently, there has been widespread interest in the use of exhaled breath condensate (EBC) as a fully noninvasive methodology for the assessment of inflammation in a variety of lung diseases, including chronic obstructive pulmonary disease (COPD), cystic fibrosis, bronchiectasis, primary ciliary dyskinesia and asthma. Analysis of EBC has used a variety of sensitive methods, including ELISA [1], multiplex ELISAs [1] and, more recently, mass spectroscopy [2].

However, most investigators have used commercial ELISAs to determine mediator concentrations as they have the advantage of easy availability, simple methodologies and good reproducibility, and come "ready validated". Assay validation relates to a number of performance criteria, such as the lower limit of detection (LLD), reproducibility as determined by the coefficient of variation (CV; both intra- and interassay), linearity, spike return, performance in the media being assessed and specificity. However, commercial validation procedures do not describe the performance aspects of the assay within the relevant biological samples for differing disease states. Furthermore, the validation does not define lower limit of quantification (LLQ), which will also vary according to the biological fluid and the research requirements. The very low mediator concentrations commonly reported in EBC may, therefore, require a sensitivity not appreciated in the validation of a conventional commercial ELISA. This is especially important as the conventional validation of ELISA reproducibility is often only undertaken at concentrations on the linear section of the typical sigmoid curve for mediator concentration to signal. The variability of measurements increases greatly outside this linear portion and is particularly relevant for measurements at or around the LLD.

A variety of inflammatory mediators have previously been assessed in EBC in a range of lung diseases. Most interest has been focused upon the eicoinasoid leukotriene (LT) $B_{4}$, typically measured using a commercial ELISA from Cayman Chemical Company (Ann Arbor, MI, USA). Concentrations reported in stable COPD range from a median value of $10.6 \mathrm{pg} \cdot \mathrm{mL}^{-1}$ [3] to $100.6 \mathrm{pg} \cdot \mathrm{mL}^{-1}$ [1]. IZQUIERDO et al. [4] reported $\mathrm{LTB}_{4}$ concentrations at $\leqslant 1.1 \mathrm{pg} \cdot \mathrm{mL}^{-1}$, despite suggesting that the samples below the LLD were
AFFILIATIONS

*Dept of Medicine, University of Birmingham, and

\#Queen Elizabeth Hospital,

Birmingham, UK.

CORRESPONDENCE

D.L. Bayley

Dept of Medicine

University of Birmingham

Edgbaston

Birmingham

B15 2TH

UK

Fax: 441216272012

E-mail: bayleydl@hotmail.com

Received:

July 032007

Accepted after revision:

January 122008

STATEMENT OF INTEREST

A statement of interest for

R.A. Stockley can be found at

www.erj.ersjournals.com/misc/

statements.shtml

European Respiratory Journal

Print ISSN 0903-1936

Online ISSN 1399-3003 
recorded as undetectable (the LLD specified by the assay manufacturers was $13 \mathrm{pg} \cdot \mathrm{mL}^{-1}$ ). Limited data is available concerning assay validation at these low levels, although LEUNG et al. [5] suggested that the assay is not reproducible at the concentrations found in EBC. Measurement of $\mathrm{LTB}_{4}$ by mass spectroscopy found that $\mathrm{LTB}_{4}$ could be detected in patients with asthma who were not on therapy (LLQ given as lowest calibrator; $\left.100 \mathrm{pg} \cdot \mathrm{mL}^{-1}\right)$. Conversely, PANCHAUD et al. [3] suggested that the calibration curve for the assay is linear between $165-990 \mathrm{pg} \cdot \mathrm{mL}^{-1}$; thus, quantification should be less robust outside this range.

The assessment of interleukin (IL)-8 in EBC has received less attention. IZQUIERDO et al. [4] described lower concentrations of IL-8 in EBC from emphysematous subjects $\left(0.34 \mathrm{pg} \cdot \mathrm{mL}^{-1}\right)$, compared with chronic bronchitics $\left(2.32 \mathrm{pg} \cdot \mathrm{mL}^{-1}\right)$ and controls (3.32 $\left.\mathrm{pg} \cdot \mathrm{mL}^{-1}\right)$. ZIHLIF et al. [6] suggested that IL-8 concentrations were undetectable in both children with primary ciliary dyskinesia and controls. SIMPSON et al. [7] described detectable IL-8 in smokers but questioned the validity of the ELISA, whereas SACK et al. [1] were able to measure IL-8 in EBC using a multiplex system. However, very little information is available concerning other proteins such as $\alpha_{1}$-antitrypsin (AAT), secretory leukoprotease inhibitor (SLPI), myeloperoxidase (MPO) or other inflammatory cytokines in EBC.

The present study sought to determine whether it was possible to validate a series of assays for use in the measurement of mediators in EBC. The assays under investigation were: commercial ELISAs for $\mathrm{LTB}_{4}$ (GE Healthcare Life Sciences, Little Chalfont, UK and Cayman Chemical Company) and for IL-8 and SLPI (R\&D Systems Europe Ltd, Abingdon, UK); an in-house ELISA for AAT; and a chromogenic activity assay for MPO. In addition, results in EBC were compared with those found in matched, spontaneous, sol phase sputum samples from the same patient on the same day, to determine whether the EBC level reflected the results of airway secretions.

\section{METHODS}

\section{Study subjects}

In total, 61 subjects were recruited for the study: 12 patients with bronchiectasis (confirmed on high-resolution computed tomography), 19 patients with COPD, and 30 normal subjects with normal spirometry and no history of lung disease. All subjects were assessed in a stable state (no antibiotics or oral corticosteroids for $\geqslant 2$ months). Of the 19 COPD patients, 12 fulfilled standard criteria for the diagnosis of chronic bronchitis (CB; daily sputum production for $\geqslant 3$ months of 2 consecutive yrs) [8]. Patients with underlying immune deficiency, allergic bronchopulmonary aspergillosis or cystic fibrosis were excluded from the study.

\section{Assessment and investigations}

EBC was obtained using RTube ${ }^{\mathrm{TM}}$ apparatus (Respiratory Research, Charlottesville, VA, USA) for a collection period of $20 \mathrm{~min}$ at $-40^{\circ} \mathrm{C}$, and was stored at $-70^{\circ} \mathrm{C}$ until analysed. Collection was conducted with reference to the recommendations set out by HoRVÁth et al. [9]. Matched, spontaneous sputum sol phase was obtained from nine of the subjects with COPD and $C B$, and nine of the subjects with bronchiectasis. Sputum was collected in sterile containers over a 4 -h period in the morning after rising. The sputum was ultracentrifuged at
$50,000 \times g$ for $90 \mathrm{~min}$ at $4{ }^{\circ} \mathrm{C}$, and the sol phase was removed and stored at $-70^{\circ} \mathrm{C}$ until analysed.

Following EBC collection, all subjects underwent spirometry with reversibility (20 min before and after inhalation of $400 \mu \mathrm{g}$ of salbutamol) [10]. Post-bronchodilator forced expiratory volume in one second (FEV1) was expressed as percentage of the predicted normal reference values [11].

\section{Assays on sputum sol phase and EBC}

Mediator quantification was determined by interpolation of the signal from a standard curve of known concentrations. The intra- and interassay CV was determined for a pooled sample of EBC and samples prepared from the mediator standard measured on six occasions. In addition, recovery was determined in both EBC and standard buffer by comparing the assay result with that expected from a known mediator spike [12]. Briefly, single samples or pure mediators were assayed on six occasions to obtain the intra-assay CV. At this point, a known quantity of the pure mediator was added to the sample, which was re-assayed. The result was compared with the standard curve and the new value was obtained by interpolation. This second value was subtracted from the predicted value to obtain the proportion "recovered".

The LLD for an assay was defined as $2 \mathrm{SD}$ above the mean signal for 20 sample blanks. The LLQ was defined as the point at which both intra- and interassay $\mathrm{CV}$ and spike recovery became acceptable for each assay $(<12 \%)$. This concept is demonstrated for the SLPI ELISA in figure 1. All EBC samples were analysed without dilution.

The methods for $\mathrm{LTB}_{4}$ (GE Bioscience), SLPI and MPO have been described in detail previously [12]. The second commercial $\mathrm{LTB}_{4}$ ELISA (Cayman Chemical Company) was used according to the manufacturer's instructions.

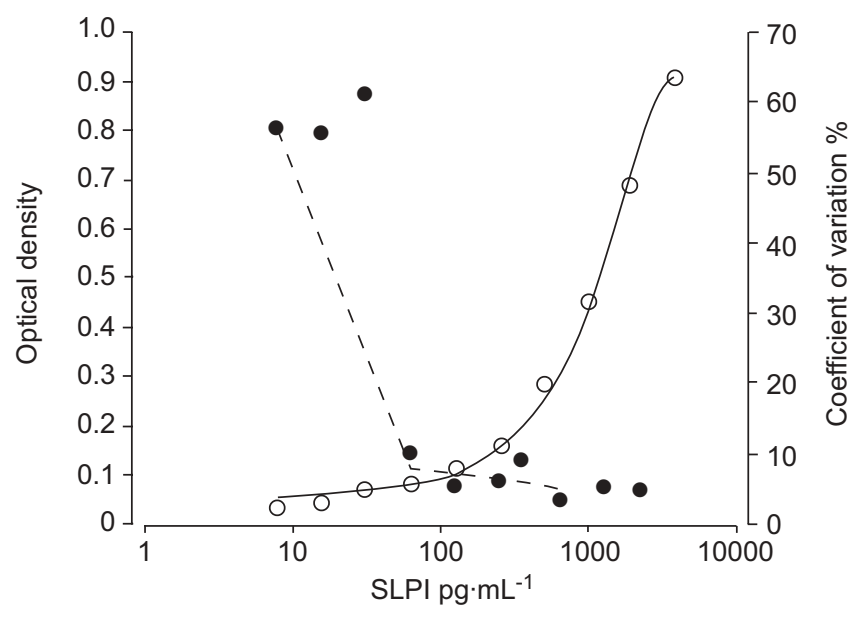

FIGURE 1. The performance of the secretory leukoprotease inhibitor (SLPI) assay is shown. The optical density of the ELISA $(\bigcirc)$ is related to the concentration of protein, a typical sigmoid curve is demonstrated (-). The coefficient of variation (-) of sample measurements at different SLPI concentrations is described. A major increase in the variability of the repeated measures is seen for the plateau of the curve $(---)$ 
IL-8 was measured by ELISA using a commercially available kit (R\&D Systems Europe Ltd). The sol phase intra-assay CV was $<8.5 \%$ throughout the working range of the assay. Sputum samples spiked with IL-8 resulted in $>88 \%$ recovery.

AAT was measured by an in-house ELISA relative to a commercially available serum standard (The Binding Site Limited, Birmingham, UK). In brief, $200 \mu \mathrm{L}$ of anti-human AAT (The Binding Site Limited) in $0.05 \mathrm{M}$ sodium carbonate/ bicarbonate $\mathrm{pH} 9.6$ was added to a Nunc MAXISORP (Loughborough, UK) microtitre plate and incubated overnight at $4^{\circ} \mathrm{C}$. The plate was then washed three times with PBS containing 1\% (v/v) Tween 20 (Sigma-Aldrich Company Ltd, Poole, Dorset, UK) and $0.5 \%(\mathrm{w} / \mathrm{v})$ dried skimmed milk (PBS$\mathrm{T}), 200 \mu \mathrm{L}$ of standard or sample was added to the plate, and it was then incubated for $1 \mathrm{~h}$ at $37^{\circ} \mathrm{C}$. The plate was again washed three times with PBS-T, then $200 \mu \mathrm{L}$ of anti-human AAT peroxidase conjugate (The Binding Site Limited) in PBS-T was added to each well, and the plate was incubated for $1 \mathrm{~h}$ at $37^{\circ} \mathrm{C}$. Following three more washes with PBS-T, $200 \mu \mathrm{L}$ of 3,3',5,5'tetramethylbenzidine ELISA substrate solution (Sigma-Aldrich Company Ltd) was then added to each well and incubated for $10 \mathrm{~min}$ at $25^{\circ} \mathrm{C}$. The reaction was stopped with $50 \mu \mathrm{L}$ of $0.1 \mathrm{M}$ $\mathrm{H}_{2} \mathrm{SO}_{4}$ and the plate was read at $450 \mathrm{~nm}$ with a $570 \mathrm{~nm}$ correction, and the AAT concentration obtained by interpolation from the standard curve. The sol phase intra-assay CV was $<10.2 \%$ throughout the working range of the assay and sputum samples spiked with AAT gave $>85 \%$ recovery.

\section{Statistics}

Normally distributed data were expressed as mean \pm SD and the patient groups were compared using one-way ANOVA, with the Bonferroni correction being used if significant differences were detected. Correlations between matched sol phase sputum and EBC samples were assessed by Spearman rank correlation. Statistical significance was accepted at $\mathrm{p}<0.05$.

\section{RESULTS}

\section{Baseline characteristics}

Baseline characteristics are shown in table 1 . The mean \pm SD age of COPD and bronchiectasis patients was similar (67.1 \pm 7.6 and $67.7 \pm 5.3 \mathrm{yrs}$, respectively; $\mathrm{p}=1$ ). Normal subjects were

\begin{tabular}{|c|c|c|c|}
\hline & Normal & COPD & Bronchiectasis \\
\hline \multicolumn{4}{|l|}{ Subjects $\mathrm{n}$} \\
\hline Total & 30 & 19 & 12 \\
\hline Females & 11 & 8 & 6 \\
\hline Age yrs & $50 \pm 8$ & $67 \pm 5.3$ & $67 \pm 7.6$ \\
\hline $\mathrm{FEV}_{1} \%$ pred & $107 \pm 13.2$ & $48.9 \pm 14.7$ & $70.3 \pm 25.8$ \\
\hline Height m & $1.69 \pm 0.09$ & $1.68 \pm 0.05$ & $1.66 \pm 0.09$ \\
\hline \multicolumn{4}{|l|}{ Smoking history $\mathbf{n}$} \\
\hline Current smokers & 9 & 6 & 0 \\
\hline Ex-smokers & 3 & 13 & 3 \\
\hline Nonsmokers & 18 & 0 & 9 \\
\hline \multicolumn{4}{|c|}{$\begin{array}{l}\text { Data are presented as mean } \pm \mathrm{SD} \text {, unless otherwise stated. COPD: chronic } \\
\text { obstructive pulmonary disease; FEV } 1 \text { : forced expiratory volume in one second; } \\
\% \text { pred: \% predicted. }\end{array}$} \\
\hline
\end{tabular}

significantly younger $(50 \pm 8$ yrs $)$ than both COPD $(p<0.001)$ and bronchiectasis $(\mathrm{p}<0.001)$ groups. Patients with COPD had a significantly lower FEV1 \% predicted $(48.9 \pm 14.7 \%)$ compared with both normal subjects $(107 \pm 13.2 \%$; $<<0.001)$ and patients with bronchiectasis $(70.3 \pm 25.8 \% ; \mathrm{p}=0.007)$. Patients with bronchiectasis had a lower FEV1 compared with normal subjects $(\mathrm{p}<0.001)$. The majority of COPD patients were either Global Initiative for Chronic Obstructive Lung Disease (GOLD) [13] stage $2(42.1 \%)$ or stage $3(47.4 \%)$. The remaining two $(10.5 \%)$ patients were GOLD stage 4 . All patients in the bronchiectasis group had an idiopathic disease (no evidence of causative/susceptibility factors such as AAT or immunoglobulin deficiencies, allergic bronchopulmonary aspergillosis, ciliary dyskinesia, etc.).

\section{Assays on sputum sol phase and EBC}

All assays had an intra- and interassay CV of $<15 \%$ in the linear part of the standard curve and $>85 \%$ spike recovery.

\section{$\mathrm{LTB}_{4}$}

The LLD for the $\mathrm{LTB}_{4}$ ELISA (GE Bioscience) was $7 \mathrm{pg} \cdot \mathrm{mL}^{-1}$, which was also consistent with the manufacturer's value of $\sim 6 \mathrm{pg} \cdot \mathrm{mL}^{-1}$. Quantification was acceptable at $20 \mathrm{pg} \cdot \mathrm{mL}^{-1}$, when the intra-assay $\mathrm{CV}$ became $<12 \%$ and spike recovery reached $77 \%$. At values $<20 \mathrm{pg} \cdot \mathrm{mL}^{-1}$, the intra-assay $\mathrm{CV}$ ranged from $21.4 \%$ at $12 \mathrm{pg} \cdot \mathrm{mL}^{-1}$ to $111.4 \%$ at $1.6 \mathrm{pg} \cdot \mathrm{mL}^{-1}$, with spike recoveries of between $81.8 \%$ at $12 \mathrm{pg} \cdot \mathrm{mL}^{-1}$ and $12.7 \%$ at $1.6 \mathrm{pg} \cdot \mathrm{mL}^{-1}$. Samples from only 19 subjects (12 controls, three COPD and $\mathrm{CB}$, and four bronchiectatic patients) of the 61 study subjects had values that exceeded the LLD of the assay. However, no sample values exceeded the LLQ of the assay (fig. 2a).

The present authors also assessed a second $\mathrm{LTB}_{4}$ assay (Cayman Chemical Company) and found that the LLD for this assay was $9.2 \mathrm{pg} \cdot \mathrm{mL}^{-1}$, which was consistent with the value reported by the manufacturer $\left(\sim 13 \mathrm{pg} \cdot \mathrm{mL}^{-1}\right)$. Quantification, however, only became acceptable at $30 \mathrm{pg} \cdot \mathrm{mL}^{-1}$, where the intra-assay $\mathrm{CV}$ was $<12 \%$ and spike recovery was $86 \%$. At values $<20 \mathrm{pg} \cdot \mathrm{mL}^{-1}$, the intra-assay $\mathrm{CV}$ ranged from $21.4 \%$ at $16 \mathrm{pg} \cdot \mathrm{mL}^{-1}$ to $68.6 \%$ at $2.5 \mathrm{pg} \cdot \mathrm{mL}^{-1}$.

\section{IL-8}

The LLD for the IL-8 ELISA was consistent with the manufacturer's value of $\sim 10 \mathrm{pg} \cdot \mathrm{mL}^{-1}$. Quantification became acceptable at $40 \mathrm{pg} \cdot \mathrm{mL}^{-1}$, where the intra-assay $\mathrm{CV}$ was $<12 \%$ and spike recovery was $>88 \%$. Below $40 \mathrm{pg} \cdot \mathrm{mL}^{-1}$ the intra-assay $\mathrm{CV}$ ranged from $13.9 \%$ at $30 \mathrm{pg} \cdot \mathrm{mL}^{-1}$ to $90.7 \%$ at $8 \mathrm{pg} \cdot \mathrm{mL}^{-1}$, with spike recoveries of between $57.6 \%$ at $31 \mathrm{pg} \cdot \mathrm{mL}^{-1}$ and $6.1 \%$ at $3.9 \mathrm{pg} \cdot \mathrm{mL}^{-1}$. Samples from only four out of 61 subjects (two controls, one COPD, and one bronchiectatic individual) exceeded the LLD of the assay, but no sample reached the assay LLQ (fig. 2b).

\section{SLPI}

The LLD for the SLPI ELISA $\left(25.5 \mathrm{pg} \cdot \mathrm{mL}^{-1}\right)$ was consistent with the manufacturer's value of $\sim 25 \mathrm{pg} \cdot \mathrm{mL}^{-1}$. Quantification became acceptable at $100 \mathrm{pg} \cdot \mathrm{mL}^{-1}$, where the intra-assay $\mathrm{CV}$ was $<12 \%$ and spike recovery was $102.8 \%$. At values $<100 \mathrm{pg} \cdot \mathrm{mL}^{-1}$, the intra-assay $\mathrm{CV}$ ranged from $10.2 \%$ at $62 \mathrm{pg} \cdot \mathrm{mL}^{-1}$ to $56.2 \%$ at $8 \mathrm{pg} \cdot \mathrm{mL}^{-1}$, while spike return varied from $78 \%$ at $62 \mathrm{pg} \cdot \mathrm{mL}^{-1}$ to $-60 \%$ at $8 \mathrm{pg} \cdot \mathrm{mL}^{-1}$. The relationship between the assay $\mathrm{CV}$ and the linear part of the ELISA sigmoid 

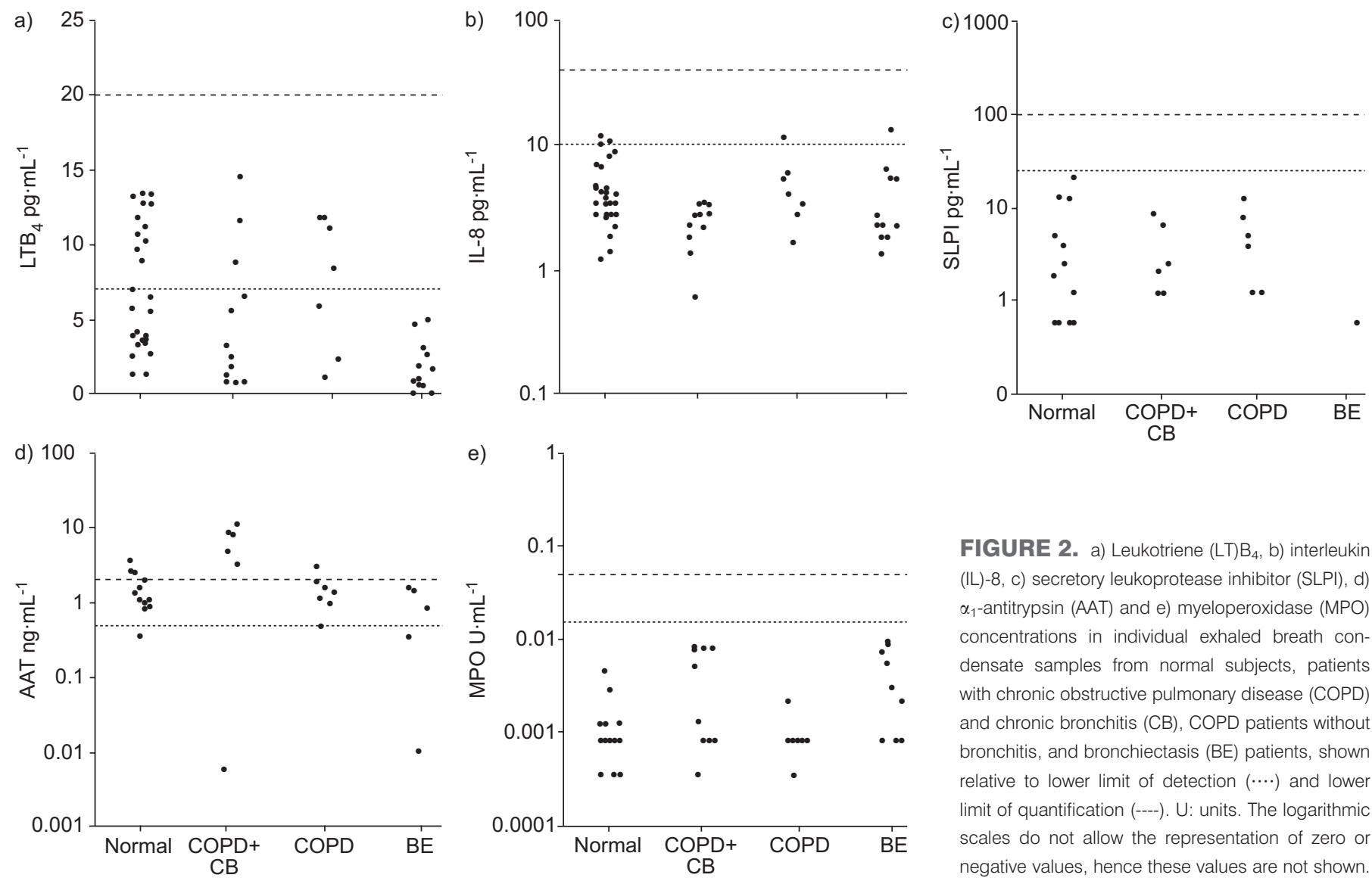

FIGURE 2. a) Leukotriene (LT)B $\mathrm{B}_{4}$, b) interleukin (IL)-8, c) secretory leukoprotease inhibitor (SLPI), d) $\alpha_{1}$-antitrypsin (AAT) and e) myeloperoxidase (MPO) concentrations in individual exhaled breath condensate samples from normal subjects, patients with chronic obstructive pulmonary disease (COPD) and chronic bronchitis (CB), COPD patients without bronchitis, and bronchiectasis (BE) patients, shown relative to lower limit of detection $(\cdots \cdot)$ and lower limit of quantification (----). U: units. The logarithmic scales do not allow the representation of zero or negative values, hence these values are not shown.

curve is shown in figure 1. No samples from the 46 subject samples for which this was assayed reached either the LLD or the LLQ (fig. 2c).

\section{AAT}

The in-house AAT ELISA had an LLD of $0.8 \mathrm{ng} \cdot \mathrm{mL}^{-1}$. Quantification was acceptable at $2 \mathrm{ng} \cdot \mathrm{mL}^{-1}$, when the intraassay $\mathrm{CV}$ was $<12 \%$ and spike recovery was $>77 \%$. At values $<2 \mathrm{ng} \cdot \mathrm{mL}^{-1}$, the intra-assay $\mathrm{CV}$ ranged from $55.5 \%$ at $0.5 \mathrm{ng} \cdot \mathrm{mL}^{-1}$ to $119.2 \%$ at $0.03 \mathrm{ng} \cdot \mathrm{mL}^{-1}$, while spike recovery ranged from $75.5 \%$ at $1.75 \mathrm{ng} \cdot \mathrm{mL}^{-1}$ to $54.4 \%$ at $0.2 \mathrm{ng} \cdot \mathrm{mL}^{-1}$. In total, 46 samples were assayed. Samples from 28 of the subjects (13 controls, five COPD and CB, six COPD, and four bronchiectatic individuals) reached the LLD of the assay. Samples from nine subjects (three controls, five COPD, with $\mathrm{CB}$ and one COPD patient) exceeded the LLQ of the assay (fig. $2 \mathrm{~d}$ ).

\section{MPO}

The LLD for the MPO activity assay was 0.015 units $\cdot \mathrm{mL}^{-1}$. Quantification became acceptable at 0.05 units $\cdot \mathrm{mL}^{-1}$, at which point the intra-assay $\mathrm{CV}$ was $<4.59 \%$ and spike recovery was $103.34 \%$. Samples from 52 subjects were assayed. No samples reached either LLD or LLQ (fig. 2e).

\section{Correlation with sputum}

If the issues raised previously are not appreciated, interpolation of the signal from the standard dose-response curve would provide apparent "values" in the detectable range. For example, the $\mathrm{LTB}_{4}$ levels, when above the LLD, would be on average $11.3 \mathrm{pg} \cdot \mathrm{mL}^{-1}$, by interpolation using the linear part of the standard curve (similar to levels reported in the literature). However, even when these derived values were related to the sputum value for the same patient sample, there was no significant direct correlation for any mediator, when corrected for the effects of multiple analyses (table 2).

\section{DISCUSSION}

The collection of EBC is thought to provide a valuable noninvasive technique to measure inflammatory mediators within the airways. However, the assays described in the present study show that extreme care needs to be taken when interpreting mediator results in this fluid. All of the ELISAs described confirm poor reproducibility for values derived from below the linear part of the sigmoid curve of standard quantity to signal described by an ELISA. This is understandable, as small variations in the optical density at this point can result in large changes in the value derived by interpolation and confirmed by variable and unreliable spike recovery results. The most accepted definition of LLQ is the lowest concentration that can be measured with a definite level [14]. The LLQ described in the present study was the value above which the intra-assay CV was shown to be $<12 \%$ and the spiked mediator recovery was $>80 \%$, and assay characteristics were clearly linear. Samples from only $19.6 \%$ of the subjects in the present study were within these criteria, and for only one assay (AAT). 


\begin{tabular}{|c|c|c|}
\hline TABLE 2 & \multicolumn{2}{|c|}{$\begin{array}{l}\text { Spearman rank correlations of inflammatory } \\
\text { mediator concentrations between sol phase } \\
\text { sputum and exhaled breath condensate }\end{array}$} \\
\hline Mediator & $\mathrm{p}$-value & $\mathbf{n}$ \\
\hline LTB $_{4}$ & 0.185 & 18 \\
\hline IL-8 & 0.440 & 18 \\
\hline SLPI & 0.140 & 15 \\
\hline AAT & 0.211 & 18 \\
\hline MPO & 0.324 & 18 \\
\hline \multicolumn{3}{|c|}{$\begin{array}{l}\mathrm{LTB}_{4} \text { : leukotriene } \mathrm{B}_{4} \text {; IL: interleukin; SLPI: secretory leukoprotease inhibitor; } \\
\text { AAT: } \alpha_{1} \text {-antitrypsin; MPO: myeloperoxidase. One-tailed p-values are shown. A } \\
\text { p-value }<0.05 \text { was considered significant. Spearman rank correlation did not } \\
\text { reach significance for any mediator. }\end{array}$} \\
\hline
\end{tabular}

There has been very little data published regarding the validation of assays used in EBC at very low concentrations. SLPI, AAT and MPO activity measurements have not previously been reported in EBC.

In the present study, the sol phase of spontaneous sputum was chosen as a read-out for mediator concentrations found within the lungs. Currently, no obvious "gold standard" exists for reference of the EBC mediator concentrations with those found within the lungs [15]. EBC reflects air from the whole bronchial tree. However, airway secretions (in particular spontaneous sputum) contain high levels of mediators. As EBC and sputum were collected from the same patients, this was felt to be the best comparison. In addition, the data by BIERNACKI et al. [16] demonstrated that EBC $\mathrm{LTB}_{4}$ is increased in exacerbation of COPD and falls upon resolution. Since exacerbations of COPD are events affecting the bronchial tree, and since similar changes occur in sputum, this is the most appropriate sample for comparative purposes [17].

It is possible that EBC also reflects changes in the distal airways and hence comparison with bronchoalveolar lavage (BAL) would be appropriate, even in light of the lack of relationship with BAL demonstrated by JACKSON et al. [15]. However, it seems inappropriate to assess this until valid assays are identified for EBC.

In order to enable reliable mediator determination, it might be argued that concentrating the EBC is necessary, although such procedures may also prove inaccurate due to protein loss [18] and other confounding factors, such as unknown stability of $\mathrm{LTB}_{4}$ in EBC when lyophilised [9]. The results described in the current study suggest that EBC cannot be used to determine mediator concentrations either within a study or as a diagnostic tool, via the present assays and collection techniques.

Although the current results question the validity and conclusions drawn from other studies involving the mediators assessed here, EBC may still prove a useful tool. Assays, such as IL-6, might detect quantifiable levels in EBC, and other biomarkers may prove measurable by current methodologies.

The use of other collection equipment, or the application of coatings to the collection equipment to prevent binding of mediators, may be necessary. For example, RosiAs et al. [19] have shown that glass and silicone were superior to aluminium, polypropylene and Teflon when measuring 8-isoprostane and albumin levels in EBC. LIU et al. [20] demonstrated that the total protein levels in EBC were higher when using Ecoscreen ${ }_{\mathbb{R}}$ when compared with glass and RTube ${ }^{\mathrm{TM}}$ in collection devices, and that Ecoscreen ${ }_{\circledast}$ might prevent mediator binding. LEUNG et al. [5] have demonstrated that cysteinyl LTs and $\mathrm{LTB}_{4}$ were poorly correlated when collected using Ecoscreen ${ }$ and RTube $^{\mathrm{TM}}$. However, the effect of differing collection devices upon specific protein inflammatory mediators is unknown. Alternatively, it might be possible to prevent absorption of mediators upon the collection equipment by pre-blocking with agents such as bovine serum albumin, although this might in itself cause reproducibility issues.

The presence of proteinases, receptors, antibodies and other interfering proteins, along with variations in $\mathrm{pH}$ and protein concentration, ensure that sputum is a challenging matrix for mediator measurement. However, the high mediator concentrations present often enable deleterious effects upon ELISAs to be substantially negated by dilution, as has been shown for secretory proteinase inhibitor in the presence of neutrophil elastase [21]. Critically, this is not possible in EBC at present.

The alternatives are to develop more sensitive ELISA assays, proteomics or mass spectroscopy measurements. However, with more sensitive assays a balance in the signal/noise ratio will need to be taken into account [9].

The results of the present study indicate that the performance of any assay must be fully characterised in order to interpret the results. The current study investigated both ELISA and chromogenic substrate techniques; however, the validation methodologies are also critical for all methodologies used for the assessment of mediators within exhaled breath condensate.

\section{REFERENCES}

1 Sack U, Scheibe R, Wötzel M, et al. Multiplex analysis of cytokines in exhaled breath condensate. Cytometry A 2006; 69: 169-172.

2 Montuschi P, Macagno F, Parente P, et al. Effects of cyclooxygenase inhibition on exhaled eicosanoids in patients with COPD. Thorax 2005; 60: 827-833.

3 Panchaud A, Avois L, Roulet M, et al. A validated liquid chromatography-mass spectrometry method for the determination of leukotrienes B4 and B5 produced by stimulated human polymorphonuclear leukocytes. Anal Biochem 2005; 341: 58-68.

4 Izquierdo JL, Almonacid C, Parra T, Pérez J. [Systemic and lung inflammation in 2 phenotypes of chronic obstructive pulmonary disease]. Arch Bronconeumol 2006; 42: 332-337.

5 Leung TF, Li CY, Yung E, Liu EK, Lam CW, Wong GW. Clinical and technical factors affecting $\mathrm{pH}$ and other biomarkers in exhaled breath condensate. Pediatr Pulmonol 2006; 41: 87-94.

6 Zihlif N, Paraskakis E, Tripoli C, Lex C, Bush A. Markers of airway inflammation in primary ciliary dyskinesia studied using exhaled breath condensate. Pediatr Pulmonol 2006; 41: 509-514.

7 Simpson JL, Wood LG, Gibson PG. Inflammatory mediators in exhaled breath, induced sputum and saliva. Clin Exp Allergy 2005; 35: 1180-1185. 
8 Definition and classification of chronic bronchitis for clinical and epidemiological purposes. A report to the Medical Research Council by their Committee on the Aetiology of Chronic Bronchitis. Lancet 1965; 1: 775-779.

9 Horváth I, Hunt J, Barnes PJ, et al. Exhaled breath condensate: methodological recommendations and unresolved questions. Eur Respir J 2005; 26: 523-548.

10 Guidelines for the measurement of respiratory function. Recommendations of the British Thoracic Society and the Association of Respiratory Technicians and Physiologists. Respir Med 1994; 88: 165-194.

11 Quanjer PH, Tammeling GJ, Cotes JE, Pedersen OF, Peslin R, Yernault JC. Lung volumes and forced ventilatory flows. Report Working Party Standardization of Lung Function Tests, European Community for Steel and Coal. Official Statement of the European Respiratory Society. Eur Respir J 1993; 6: Suppl. 16, 5-40.

12 Stockley RA, Bayley DL. Validation of assays for inflammatory mediators in sputum. Eur Respir J 2000; 15: 778-781.

13 Rabe KF, Hurd S, Anzueto A, et al. Global strategy for the diagnosis, management, and prevention of chronic obstructive pulmonary disease: GOLD executive summary. Am J Respir Crit Care Med 2007; 176: 532-555.

14 Shah VP, Midha KK, Findlay JW, et al. Bioanalytical method validation - a revisit with a decade of progress. Pharm Res 2000; 17: 1551-1557.
15 Jackson AS, Sandrini A, Campbell C, Chow S, Thomas PS, Yates DH. Comparison of biomarkers in exhaled breath condensate and bronchoalveolar lavage. Am J Respir Crit Care Med 2007; 175: 222-227.

16 Biernacki WA, Kharitonov SA, Barnes PJ. Increased leukotriene B4 and 8-isoprostane in exhaled breath condensate of patients with exacerbations of COPD. Thorax 2003; 58: 294-298.

17 Gompertz S, O’Brien C, Bayley DL, Hill SL, Stockley RA. Changes in bronchial inflammation during acute exacerbations of chronic bronchitis. Eur Respir J 2001; 17: 1112-1119.

18 Afford SC, Stockley RA, Kramps JA, Dijkman JH, Burnett D. Concentration of bronchoalveolar lavage fluid by ultrafiltration: evidence of differential protein loss and functional inactivation of proteinase inhibitors. Anal Biochem 1985; 151: 125-130.

19 Rosias PP, Robroeks CM, Niemarkt HJ, et al. Breath condenser coatings affect measurement of biomarkers in exhaled breath condensate. Eur Respir J 2006; 28: 1036-1041.

20 Liu J, Conrad DH, Chow S, Tran VH, Yates DH, Thomas PS Collection devices influence the constituents of exhaled breath condensate. Eur Respir J 2007; 30: 807-808.

21 Campbell JK, McCann KP, Stewart PM, Stockley RA. The effect of sputum and its constituents on the expression and secretion of secretory leukoprotease inhibitor (SLPI). Eur Respir J 1998; 12: Suppl. 28, 398s. 